\title{
DESAFIOS DA ARQUEOLOGIA PREVENTIVA: COMO GERIR E SOCIALIZAR O IMENSO VOLUME DE MATERIAIS E DOCUMENTOS POR ELA PRODUZIDOS?
}

\author{
Solange Bezerra Caldarelli ${ }^{1}$ \\ Manuelina Maria Duarte Cândido²
}

\section{RESUMO}

O artigo discute o grande desafio que se coloca, no presente, para os responsáveis pelas pesquisas arqueológicas preventivas, associadas à Avaliação Ambiental: como gerir e socializar o imenso acervo material e documental produzido por estas pesquisas, em parceria com os órgãos de proteção ao patrimônio cultural e do campo museal.

PALAVRAS-CHAVE: musealização da arqueologia, arqueologia preventiva, impacto ambiental.

\section{ABSTRACT}

The present paper discusses the great challenge the responsible researchers in partnership with the governmental agencies of cultural protection and the museums have to face to ensure the guardianship, conservation and extroversion of the massive collection of material culture and documents produced by Preventive Archaeology in the context of Environmental Assessment.

KEYWORDS: musealization of archeology, preventive archeology, environmental impact.

\section{RESUMÉ}

L'article discute le grand défi auquel doivent faire face les responsables des recherches archéologiques préventives associées à l'Evalouation Ambientale: comment assurer la gestion et la socialization du grand volume de matériel et de documentation produite par ces recherches, conjointement avec les organes de protection au patrimoine culturel et du champ muséal.

MOTS-CLÉS: muséalisation de l'archéologie, archéologie préventive, impact environnemental.

\footnotetext{
${ }^{1}$ Doutora em Ciências Humanas (FFLCH/USP, 1984); pesquisadora do Instituto de Pré-História da USP (1977-1985); Coordenadora, pelo lado brasileiro, de Acordo de Cooperação Internacional CNPq/CNRS (1982/1985), entre o IPH-USP e a URA28-CNRS; Pesquisadora de Desenvolvimento Científico Regional/CNPq, junto ao Museu Paraense Emílio Goeldi (1986/1988); Diretora da Scientia Consultoria Científica desde 1989. E-mail: solange@scientiaconsultoria.com.br.

${ }^{2}$ Professora Adjunta do Curso de Museologia da Universidade Federal de Goiás. Licenciada em História (UECE, 1997), especialista em Museologia e mestre em Arqueologia (USP, 2000 e 2004), doutora em Museologia (ULHT, 2012). Realizou em 2014/15 estágio pós-doutoral em Museologia na Universidade Paris III - Sorbonne Nouvelle. Ex-Diretora do Departamento de Processos Museais do IBRAM. E-mail: manuelin@uol.com.br.
} 
Revista de Arqueologia Pública

\section{APRESENTAÇÃO}

Não se entrará, aqui, em discussões sobre a relevância - e a legitimidade - da Arqueologia Preventiva, que, como bem pontua Martinez (2006), vem ganhando corpo fora do tradicional âmbito acadêmico da disciplina, a par de preocupações políticas associadas às crescentes necessidades de se empreender métodos eficazes para a gestão do patrimônio arqueológico, frente aos projetos desenvolvimentistas implantados ou em implantação por todos os recantos do planeta ocupados pelo ser humano, em um infindável processo de ampliação de seu habitat, com seu imenso potencial de destruição dos testemunhos culturais e ambientais dos modos de ocupação da Terra da própria humanidade. As qualidades e defeitos das comunidades humanas, seus avanços e seus retrocessos, seus sucessos e seus fracassos, suas ações positivas e suas ações negativas, são todas elas responsáveis pelo que é a humanidade hoje e pelas alterações antrópicas do meio ambiente, por ela protagonizadas.

Acresce-se o fato de que, exatamente pelo efeito que a humanidade (espécie que mais sucesso teve na ocupação do planeta, em uma escala não igualada por nenhuma outra) teve sobre o meio ambiente, a preocupação com os bens culturais que revelam essa escalada, com suas particularidades locais, regionais e universais deixou de ser uma preocupação voltada a proteger apenas o passado humano. A preocupação ampliou-se e passou a questionar também os efeitos das consequências ambientais da jornada humana, que estão afetando o equilíbrio necessário à sobrevivência das demais espécies que compartilham com o ambiente planetário, colocando em risco o futuro da própria humanidade.

O ainda atual artigo de Zulauf (2000) pontua que o meio ambiente é o endereço do futuro para o qual haverá a maior convergência de demandas entre todas, termina enfatizando que existem meios de "desviar o caminho da humanidade da rota de colisão com o entulho gerado pela irresponsabilidade coletiva de raízes históricas e culturais" e que "quanto mais for possível acelerar o processo de transformação comportamental com relação ao meio ambiente, menor será o lamento, quando vierem a ocorrer as catástrofes engatilhadas, por não terem sido evitadas a tempo". Segundo Goergen (2014, p. 10): "O modo de relação agressivo e destruidor entre o homem e a natureza é parte intrínseca à razão moderna, utilitarista e instrumental. Os problemas ambientais decorrem, portanto, de uma postura civilizatória, em termos epistêmicos, éticos e estéticos, assumidos pela modernidade".

Os sítios arqueológicos são o testemunho dessa jornada interventiva sobre a natureza e das singularidades locais e regionais da diversidade cultural (marcada pelos 
significados simbólicos próprios do homem para explicar e dar continuidade a seus modos de vida) criadas pela humanidade para se adaptar aos múltiplos ambientes nos quais se aventurou e deles tirar os recursos para sua sobrevivência (GEERTZ, 2000; SERRA, Org., 2001):

\begin{abstract}
A impossibilidade de separar os seres humanos dos diversos ambientes por eles ocupados e conquistados acabou por levar os movimentos dos pesquisadores preocupados com a perda da diversidade cultural e adaptativa representada pelos sítios arqueológicos a se associarem aos movimentos sociais que lutavam para que as ações ambientais humanas sobre o ambiente fossem avaliadas, evitadas quando necessário, e, quando impossível, prevenidas, mitigadas, compensadas e/ou monitoradas. Assim, as ações voltadas aos bens culturais da humanidade, dentre os quais se encontram os bens arqueológicos, associaram-se às ações que estudam os impactos ambientais dos empreendimentos desenvolvimentistas, sob 0 amplo leque da Avaliação Ambiental, a qual inclui a avaliação não apenas dos efeitos de empreendimentos desenvolvimentistas sobre o meio ambiente e as sociedades humanas atuais, mas também sobre os bens arqueológicos que testemunham (e podem explicar) a história da humanidade.
\end{abstract}

Inserida no contexto da Avaliação Ambiental, a arqueologia exigida pelos órgãos financiadores internacionais firmou cada vez mais a preocupação em minimizar e gerenciar os efeitos da escalada humana sobre o meio ambiente, depositário dos testemunhos materiais das múltiplas soluções culturais engendradas pela própria humanidade em seu processo de expansão e adaptação aos diversos ambientes com que se deparou, elevando exponencialmente as pesquisas arqueológicas em todo o mundo e aumentando o número de profissionais a elas dedicado. Em consequência, a quantidade de dados e de acervos materiais tem atingido uma magnitude tal que o problema de sua gestão e extroversão aflige os pesquisadores e profissionais de museus a quem, direta e/ou indiretamente, cabe decidir sobre como gerir esses acervos documentais e materiais, de modo que eles possam, ao mesmo tempo: a) ser conservados, de maneira dinâmica, acompanhando o incessante avanço tecnológico da era contemporânea e b) tornarem-se acessíveis tanto ao público leigo (interessado no conteúdo da história embutida nesses acervos) quanto ao público especializado (interessado em interpretá-lo e reinterpretá-lo, à luz das sempre renovadas percepções históricas e sociais que caracterizam as ciências humanas).

No Brasil, especificamente, o IPHAN publicou, em 2016, três portarias voltadas apenas para a questão do destino dos acervos arqueológicos, a saber: Portarias IPHAN 195/2016 (com diretrizes sobre a movimentação de bens arqueológicos em território nacional), 196/2016 (que dispõe sobre a conservação de bens arqueológicos móveis e cria o Cadastro Nacional de Instituições de Guarda e Pesquisa) e 197/2016 (que dispõe sobre procedimentos para remessa de material arqueológico para análise no exterior).

\begin{tabular}{|l|l|l|l|l|l|l} 
(C) Rev. Arqueologia Pública & Campinas, SP & v.11 & n.2 & p. 188 & Novembro/2017 & ISSN 2237-8294
\end{tabular}


É este o objetivo do presente artigo: discutir o estado atual das pesquisas arqueológicas preventivas associadas à Avaliação de Impacto Ambiental e o desafio que o acervo por elas produzido traz para:

a) os arqueólogos responsáveis pelos processos decisórios sobre o que pesquisar, o que resgatar e como documentar o processo arqueológico, do campo ao laboratório e à guarda e extroversão finais dos resultados das pesquisas, dentro das mais modernas metodologias e tecnologias disponíveis por ocasião das pesquisas;

b) os órgãos de proteção ao patrimônio cultural (no Brasil, em última instância, o IPHAN - Instituto do Patrimônio Histórico e Artístico Nacional), que têm procurado, recentemente, traçar diretrizes para assegurar que todos os dados produzidos sejam periódica e constantemente repassados para bancos de dados em conformidade com as novas tecnologias digitais que se sucedem dinamicamente, tornando inacessíveis as informações digitalizadas através de mídias que se tornam rapidamente obsoletas na contemporaneidade;

c) o campo museal, incluídos aí o Instituto Brasileiro de Museus, as instituições museais e os profissionais que atuam no âmbito da Museologia, que ao final acabam se tornando os grandes responsáveis pela manutenção, gestão e extroversão desses acervos, de maneira a torná-los acessíveis às gerações presentes e futuras, permitindo sua fruição e sua reinterpretação por todos os interessados, sejam eles amadores, profissionais ou membros das comunidades, a partir das novas preocupações sociais e perspectivas teóricas que se sucedem ininterruptamente no dinâmico domínio das ciências humanas.

\section{BREVE HISTÓRICO DA ASCENSÃo DA ARQUEOLOGIA PREVENTIVA AO INSTRUMENTO DA AVALIAÇÃO DE IMPACTO AMBIENTAL E SEUS DESAFIOS}

A Arqueologia Preventiva, termo adotado no presente artigo, tem/teve várias denominações ao longo do tempo, nos mais diversos países, como exemplificado a seguir: arqueologia de salvamento (rescue archaeology; archéologie de sauvetage) ${ }^{3}$; arqueologia por contrato (contract archaeology) ${ }^{4}$ gestão de recursos culturais (cultural resources management $)^{5}$, gestão de recursos arqueológicos (archaeological resources management),

\footnotetext{
${ }^{3}$ Primeira terminologia empregada, internacionalmente. Ver, a respeito: <http://pcwww.liv.ac.uk/ Sinclair/ALGY399_Site/rescue.html\#intro> (acesso em: outubro, 2015); e, para o Brasil, Chmyz, 1995.

${ }^{4}$ Ver, a respeito, inclusive sobre a terminologia e as práticas de pesquisa empregadas no Brasil, Caldarelli \& Santos, 2000.

${ }^{5}$ Terminologia empregada inicialmente nos Estados Unidos. Ver, a respeito, Schiffer \& Gumermann, Ed., 1977.
} 
expressão que torna mais específica a gestão de bens arqueológicos, uma vez que o termo mais amplo inclui também as manifestações culturais não materiais; arqueologia preventiva (archeólogie preventive) $^{6}$; arqueologia comercial (commercial archaeology) ${ }^{7}$ e arqueologia aplicada (applied archaeology), pela UCL - University College of London, que mantém o CAA - Center for Applied Archaeology ${ }^{8}$.

Procedimentos preventivos, no que concerne à Arqueologia, foram objeto de cartas e documentos similares de proteção internacional ao patrimônio arqueológico, aprovadas e divulgadas entre e pelas nações signatárias desses documentos, destacando-se as abaixo referidas:

- Carta Internacional sobre a Proteção e a Gestão do Património Arqueológico, Lausanne, ICAHM/ICOMOS/UNESCO, 1990;

- Convenção Europeia para a Proteção do Patrimônio Arqueológico, União Europeia, Valetta, 1992.

Na Europa, a Arqueologia Preventiva, embora tenha começado no século XIX, tomou impulso, conforme aborda Demoule (2012), após a Segunda Guerra Mundial, primeiramente por iniciativa de pesquisadores acadêmicos, mas a partir de 1980, na GrãBretanha, e depois em outros países da Europa Ocidental, também por consultores privados. Nos Estados Unidos, por sua vez, a Arqueologia voltada à minimização dos impactos sobre os sítios e os sistemas de sítios arqueológicos, por empreendimentos de engenharia em terras públicas, inicialmente denominada de Arqueologia de Salvamento, conforme dito acima, passa a ganhar corpo a partir dos anos 30 do século XX (GIACINTO, 2011), sendo que o termo "Gestão de Recursos Culturais", predominantemente utilizada naquele país, foi introduzida pela primeira vez pelo National Parks Service (FOWLER, 1982).

No Brasil, também sob a denominação de Arqueologia de Salvamento, a Arqueologia Preventiva teve início na década de 70 do século $\mathrm{XX}$, por iniciativa do setor hidrelétrico (CALDARELLI; SANTOS, 2000). Nos tempos pioneiros da Arqueologia Preventiva no País, foram as instituições acadêmicas que tinham arqueólogos em seus quadros que realizaram as primeiras pesquisas de salvamento arqueológico (ARAÚJO COSTA, 1983; ARAÚJO COSTA; CALDARELLI, 1988; CALDERÓN DE LA VARA et al.,

\footnotetext{
${ }^{6}$ Terminologia empregada inicialmente na França, mas também adotada por outros países europeus. Ver, a respeito, Demoule, 2012.

7 Terminologia empregada mais recentemente, inicialmente na Grã-Bretanha, mas com adoção mais restrita, internacionalmente. Ver, a respeito, Everill, 2009; Dans, 2010.

${ }^{8}$ Ver, a respeito: <https://www.ucl.ac.uk/caa> (acesso em: outubro, 2015).

${ }^{9}$ Da qual o Brasil é signatário.

\begin{tabular}{|l|l|l|l|l|l|l|}
\hline (C) Rev. Arqueologia Pública & Campinas, SP & v.11 & n.2 & p. 190 & Novembro/2017 & ISSN 2237-8294 \\
\hline
\end{tabular}
}


1977; BROCHADO; MONTICELLI, 1994; CHMYZ, 1968; COSTA, 1983; GOULART, 1997; SIMÕES, 1986) $)^{10}$.

Apenas com a publicação da Resolução CONAMA 001/1986, as pesquisas arqueológicas preventivas passaram a ser sistematicamente exigidas por empreendimentos de qualquer natureza sujeitos a licenciamento ambiental, ampliando o mercado de trabalho arqueológico no Brasil, com o surgimento, inicialmente, de arqueólogos autônomos ${ }^{11}$ e, posteriormente, de empresas especializadas em Patrimônio Cultural (latu senso) e em Arqueologia (strictu senso).

Aliás, foi a obrigatoriedade da adoção da Avaliação de Impacto Ambiental pelos órgãos internacionais financiadores de projetos desenvolvimentistas ${ }^{12}$ que incrementou, em todo o mundo ocidental, as pesquisas arqueológicas associadas à Avaliação de Impactos Ambientais dos empreendimentos projetados com impacto no solo (arqueologia terrestre) e na água (arqueologia subaquática). Tal obrigatoriedade teve dois marcos importantes: 0 primeiro foi a Conferência das Nações Unidas sobre o Meio Ambiente Humano, em Estocolmo, no ano de 1972, a qual teve como reflexo, no Brasil, a publicação da Lei da Política Nacional do Meio Ambiente (Lei 6.938/1981), implementada através da Resolução CONAMA 001/1986.

A mais importante associação internacional sobre Avaliação de Impacto Ambiental, a IAIA (International Association for Impact Assessment) ${ }^{13}$, que congrega especialistas e interessados do mundo inteiro, nasceu poucos anos depois desse evento, em 1980. Vinte anos depois da Conferência da ONU acima mencionada, teve lugar o segundo marco importante para o desenvolvimento da Arqueologia Preventiva: a Conferência das Nações Unidas sobre o Meio Ambiente e o Desenvolvimento (CNUMAD), no Rio de Janeiro, também conhecida como Eco-92, onde se ressaltou a necessidade da adoção de políticas globais, que conciliassem o desenvolvimento econômico com o princípio de desenvolvimento sustentável.

\footnotetext{
${ }^{10}$ As referências são apenas exemplificativas de projetos de salvamento arqueológico realizados, pioneiramente, em vários estados do Brasil, sem pretensão de serem exaustivas.

${ }^{11}$ A Portaria IPHAN 07/1988 teve como finalidade principal estabelecer normas para a atuação dos arqueólogos autônomos, já que o surgimento dessa categoria profissional era uma novidade no mercado de trabalho arqueológico, em que só atuavam pesquisadores acadêmicos.

12 Destacando-se, dentre estes, o Banco Mundial (http://www.worldbank.org/), através do BIRD Banco Internacional para a Reconstrução e o Desenvolvimento; o BID - Banco Interamericano de Desenvolvimento (http://www.iadb.org); o BEI - Banco Europeu de Investimento (http://www.eib.org/), e, no Brasil, o BNDES - Banco Nacional de Desenvolvimento Econômico e Social (http://www.bndes.gov.br/).

${ }^{13}$ Da IAIA (http://www.iaia.org/), derivaram-se associações importantes para os interessados no processo de avaliação ambiental no Brasil e nos demais países de língua portuguesa, a saber: a REDE de Língua Portuguesa de Avaliação de Impactos (http://www.redeimpactos.org/) e a ABAI Associação Brasileira de Avaliação de Impacto (http://avaliacaodeimpacto.org.br/).
}

\begin{tabular}{|l|l|l|l|l|l|l|}
\hline (C) Rev. Arqueologia Pública & Campinas, SP & v.11 & n.2 & p. 191 & Novembro/2017 & ISSN 2237-8294
\end{tabular} 
Da confluência das conferências das Nações Unidas sobre o Meio Ambiente e do encontro de 1990 do ICAHM/ICOMOS/UNESCO derivou a implementação de uma Arqueologia voltada à proteção do patrimônio arqueológico, dentro do processo de Avaliação de Impacto Ambiental.

Em 1989, a Lei Federal o 7.735 cria, no Brasil, o Instituto Brasileiro do Meio Ambiente e dos Recursos Naturais Renováveis (IBAMA), com a incumbência de executar ações das políticas nacionais de meio ambiente, referentes às atribuições federais, relativas ao licenciamento ambiental, ao controle da qualidade ambiental, à autorização de uso dos recursos naturais e à fiscalização, monitoramento e controle ambiental, observadas nas diretrizes emanadas do Ministério do Meio Ambiente. Em virtude da Lei 3.924/1961, que dispõe sobre os monumentos arqueológicos e pré-históricos, o IPHAN ficou responsável por fornecer as diretrizes e dar os pareceres, no que concerne às ações de controle ambiental, sobre os sítios arqueológicos existentes no território nacional, no processo de Licenciamento Ambiental. Desta responsabilidade, inicialmente ficou encarregado o DID (Departamento de Identificação e Documentação), criado em $1998^{14}$, cujas funções foram divididas, em $2004^{15}$, pelos Departamentos de Patrimônio Material e Fiscalização (DEPAM) e de Patrimônio Imaterial (DPI).

Recentemente, foi instituída a Coordenação Nacional de Licenciamento, uma unidade especial subordinada diretamente à Presidência do IPHAN, "com a atribuição principal de coordenar as atividades pertinentes; promover articulações entre o IPHAN e os demais órgãos e entidades envolvidos em processo de licenciamento ambiental; atuar de forma articulada com os Departamentos, Centro Nacional de Arqueologia e Superintendências; e consolidar as manifestações conclusivas do IPHAN nos processos de licenciamento ambiental”16.

\section{O DESAFIO DA COMPATIBILIZAÇÃO INSTITUCIONAL DOS ÓRGÃOS ENVOLVIDOS NOS RESULTADOS DA ATUAÇÃO DA ARQUEOLOGIA PREVENTIVA ASSOCIADA À AVALIAÇÃO AMBIENTAL NO BRASIL}

No Brasil, o órgão governamental encarregado de formular diretrizes sobre o patrimônio arqueológico é o Instituto do Patrimônio Histórico e Artístico Nacional (IPHAN), criado em 1937 e, atualmente, um órgão do Ministério da Cultura (MinC).

O licenciamento ambiental, por sua vez, é uma atribuição do Instituto Brasileiro do Meio Ambiente e dos Recursos Naturais Renováveis (IBAMA), em que pese a

\footnotetext{
${ }^{14}$ Decreto Federal nº 2.807, de 1998.

${ }^{15}$ Decreto Federal $n \times 5.040$, de 2004.

${ }^{16}$ Fonte: <http://portal.IPHAN.gov.br/pagina/detalhes/1033>. Acesso em: novembro, 2015.

\begin{tabular}{|l|l|l|l|l|l|l|}
\hline (C) Rev. Arqueologia Pública & Campinas, SP & v.11 & n.2 & p. 192 & Novembro/2017 & ISSN 2237-8294
\end{tabular}
} 
corresponsabilidade atribuída, no processo, a outros órgãos federais, como a Fundação Nacional do Índio (FUNAI), a Fundação Cultural Palmares (FCP), o Instituto do Patrimônio Histórico e Artístico Nacional (IPHAN) e o Ministério da Saúde, os quais estabelecem suas diretrizes para o licenciamento ambiental, nos assuntos que lhes competem, em instrumentos normativos específicos, como a Portaria Interministerial 419/2011, recentemente substituída pela Portaria Interministerial 60/2015, que levou o IPHAN a publicar uma Instrução Normativa específica sobre os temas de sua competência (IN 01/2015).

O IPHAN ${ }^{17}$ responde pela preservação do patrimônio cultural brasileiro, cabendo-lhe proteger e promover os bens culturais de forma a assegurar sua permanência e usufruto para as gerações presentes e futuras. Esta autarquia possui em sua estrutura o Centro Nacional de Arqueologia (CNA), subordinado ao Departamento de Patrimônio Material e Fiscalização (DEPAM), ao qual cabe "a elaboração de políticas e estratégias para a gestão do Patrimônio Arqueológico Brasileiro, a modernização dos instrumentos normativos e de acompanhamento das pesquisas arqueológicas que, em duas décadas, aumentaram de cinco para quase mil ações por ano" ${ }^{18}$. O patrimônio arqueológico é, por definição, bem da Nação, protegido pelo IPHAN desde sua criação, mas notadamente pela Lei ํo 3.924/1961 e pela Constituição Brasileira vigente (1988), artigos 20 (X) e 216 (V).

Em 2009, foi criado - a partir de um então Departamento do IPHAN - o Instituto Brasileiro de Museus, também pertencente ao MinC, que assumiu os deveres e obrigações relacionados aos museus federais, originalmente sob responsabilidade do IPHAN, administrando diretamente os 29 museus do Ministério da Cultura. Também é o IBRAM a instituição responsável pela Política Nacional de Museus (PNM) e pela melhoria dos serviços do setor; pelo fomento de políticas de aquisição e preservação de acervos e pela criação de ações integradas entre os museus brasileiros ${ }^{19}$. Sua atuação, portanto, toca indistintamente as diferentes naturezas e tipologias de acervos musealizados, não havendo, em sua estrutura, uma área específica devotada ao patrimônio arqueológico. Entretanto, talvez fosse interessante que esta autarquia compartilhasse com o IPHAN a responsabilidade de avaliar as boas práticas na curadoria, guarda e extroversão do rico acervo arqueológico gerado pelas pesquisas arqueológicas no País.

Como o IBAMA é o órgão diretamente responsável pelo licenciamento ambiental no Brasil e o presente artigo se volta, especificamente, pela Arqueologia associada a este

\footnotetext{
$17<$ www.IPHAN.gov.br>.

${ }^{18}$ Fonte: <www.IPHAN.gov.br>. Acesso em: novembro, 2015.

${ }^{19}$ Fonte: <www.IBRAM.gov.br>. Acesso em: novembro, 2015.

\begin{tabular}{|l|l|l|l|l|l|l|}
\hline (C) Rev. Arqueologia Pública & Campinas, SP & v.11 & n.2 & p. 193 & Novembro/2017 & ISSN 2237-8294 \\
\hline
\end{tabular}
} 


\section{Revista de Arqueologia Pública}

instrumento, a reflexão a seguir busca localizar as intersecções entre os dois órgãos do MinC aos quais o acervo arqueológico interessa, a saber: o IPHAN e o IBRAM.

Em tese, há uma interseção importante entre as duas autarquias em relação ao patrimônio arqueológico, quando considera-se que uma ferramenta poderosa de preservação é a musealização ${ }^{20}$.

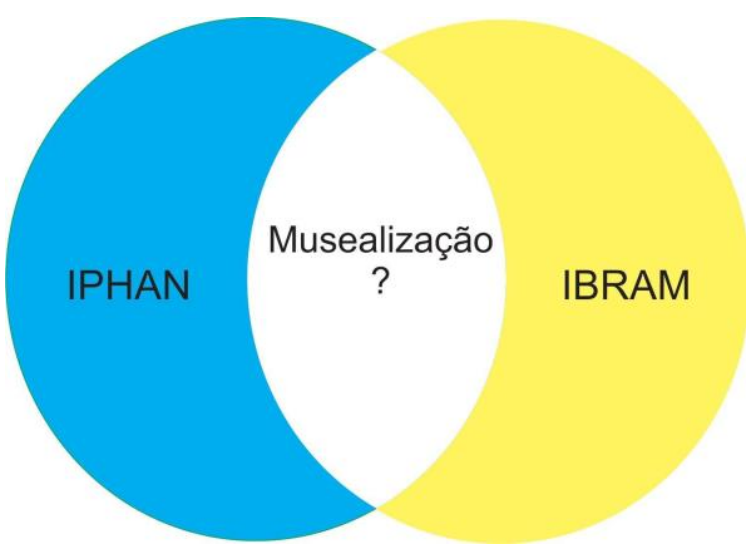

Figura 1. Musealização da Arqueologia, situação desejável: um campo forte de interseção entre IPHAN e IBRAM.

Entretanto, a normatização recente do licenciamento ambiental no Brasil tem escapado ao uso dos termos "museu" e "musealização", de forma que o patrimônio arqueológico "armazenado" para o futuro não dialoga necessariamente com as diretrizes para o campo museal traçadas pelo IBRAM e também disseminadas pelos 15 cursos de bacharelado, cinco cursos de mestrado e um de doutorado em Museologia que atualmente existem no País.

Embora autores indiquem ser necessário um olhar museológico para a problemática em questão, uma vez que os milhares de vestígios gerados pelas pesquisas arqueológicas fatalmente serão herdados por instituições museológicas (BRUNO, 1999; MORAES WICHERS, 2010; DUARTE CÂNDIDO, 2013, entre outros), não se tem observado, no Brasil, uma política concretamente preocupada com opções de guarda de acervos que incluam a marca da musealização.

\footnotetext{
${ }^{20}$ Vale reiterar que preservação, no sentido de musealização, envolve uma cadeia operatória completa, de salvaguarda e comunicação; portanto, a extroversão já está implícita como etapa imprescindível do processo.
} 


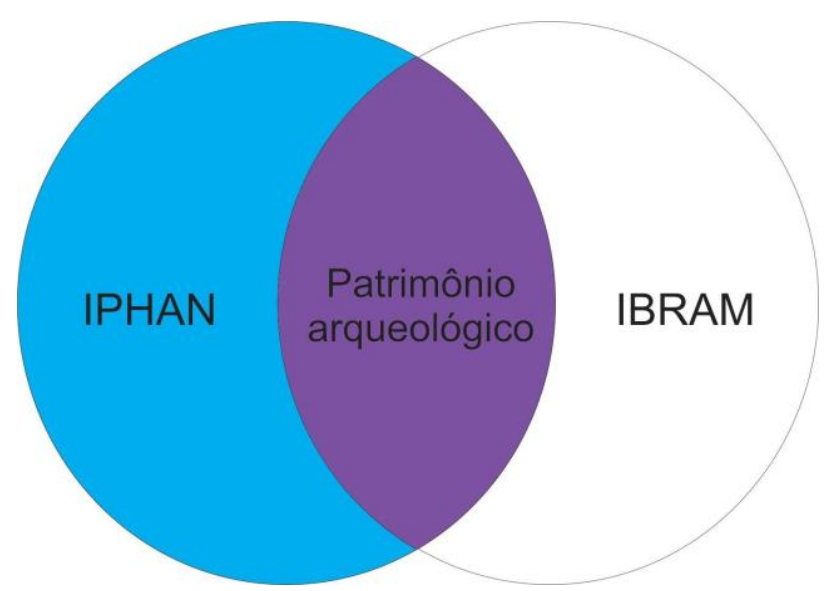

Figura 2. Patrimônio arqueológico: um domínio sob tutela predominante do IPHAN.

O órgão regulador do campo museal no Brasil, o Instituto Brasileiro de Museus (IBRAM), não tem sido partícipe, na mesma medida em que o Instituto do Patrimônio Histórico e Artístico Nacional (IPHAN), da gestão do patrimônio arqueológico, a não ser nas cerca de $14 \%$ das instituições relacionadas no Cadastro Nacional de Museus (CNM), que declaram possuir acervo arqueológico (SANTOS, 2011). A autora conclui que este cenário acaba por não espelhar a realidade da musealização da Arqueologia no Brasil contemporâneo, por estar distante dos mais de $90 \%$ das pesquisas que estão associados a projetos de Arqueologia Preventiva (idem, p. 145), os quais não têm, em geral, resultado em processos de musealização ${ }^{21}$. Tal fato é compreensível pelo muito maior tempo de existência do IPHAN, um órgão que já contava 72 anos de atuação quando o IBRAM foi criado. As formas de colaboração entre ambas as instituições, nos oito anos de vida deste último, ainda são um processo em construção, em especial no que concerne aos bens arqueológicos.

Tendo em vista a reconhecida importância do acesso aos objetos materiais procedentes da Arqueologia Preventiva para gerar apreço pela Arqueologia naqueles que não são arqueólogos, talvez seja chegada a ocasião de se estimular um debate entre estes órgãos, sem deixar de reconhecer, entretanto, que embora com potencial de colaborar com o IPHAN na formulação de diretrizes sobre curadoria, gestão e extroversão dos acervos arqueológicos, o IBRAM não tem uma estrutura que lhe permita, no momento, assumir parcela significativa das responsabilidades sobre o tratamento do patrimônio cultural no licenciamento ambiental. Esta atividade tem sido desenvolvida pelo IPHAN há quase três

\footnotetext{
${ }^{21}$ A autora reforça que a musealização não se restringe a atividades de guarda de acervos e de educação patrimonial, como indicado na regulação recente do setor. Note-se que a referência a instituições museológicas que seriam modernizadas, ampliadas ou mesmo construídas especificamente para os fins de guarda dos acervos gerados pela pesquisa arqueológica, presente na Portaria No 230, de 17 de dezembro de 2002, do IPHAN, foi suprimida posteriormente.
} 
décadas (desde a criação do DID - Departamento de Identificação), culminando com a criação da Coordenação de Licenciamento Ambiental.

Acredita-se, apesar das limitações acima mencionadas, que o tratamento do patrimônio arqueológico pode se beneficiar de uma colaboração do IBRAM na formulação das diretrizes a serem observadas pelos empreendedores em relação ao acervo arqueológico gerado pelas pesquisas arqueológicas preventivas, na etapa de demanda da Licença de Operação, quando as instituições aptas a receberem este acervo devem estar definidas e preparadas para assumir esta função, dentro das melhores normas possíveis e com os recursos tecnológicos da atualidade.

As coleções musealizadas passam por toda uma cadeia operatória museológica ${ }^{22}$, com destaque para sua apresentação pública ${ }^{23}$ em exposições de longa e de curta duração. Estas últimas são também fundamentais pelo seu dinamismo, já que podem ser constantemente atualizadas, de forma a manter o interesse dos visitantes - locais ou em trânsito - pelos museus que as acolhem, além de incorporarem novas dimensões da pesquisa e do conhecimento produzidos a partir da cultura material resgatada e em processo dinâmico de interpretação e de reinterpretação ${ }^{24}$. Esta é uma etapa do licenciamento ambiental em que o diálogo entre ambas as instituições pode ser muito profícuo. Note-se que grande parte do que se encontra declarado como "acervo arqueológico", no CNM, consiste em acervos antigos já existentes nos museus há várias décadas, e as informações, em geral, não incorporaram o incremento das coleções a partir da Arqueologia Preventiva.

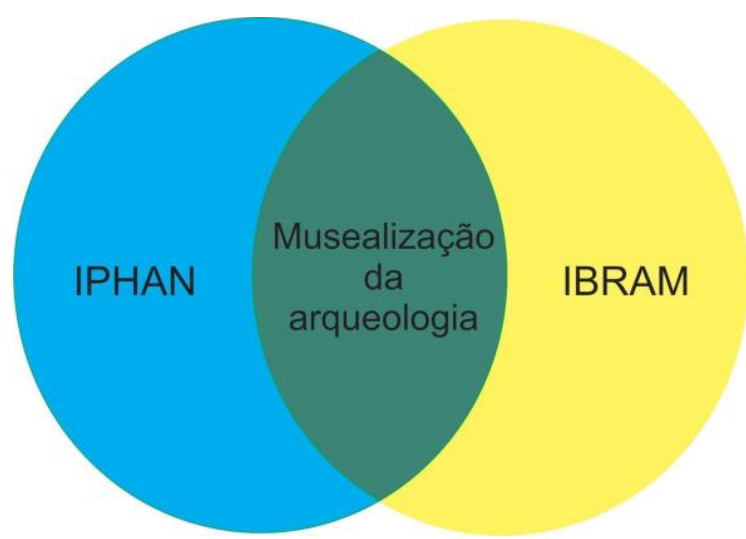

Figura 3. Musealização da Arqueologia, um domínio ainda a ser construído entre IPHAN e IBRAM.

22 Formada por procedimentos de salvaguarda (conservação preventiva e documentação museológica - que possui especificidades em relação à documentação feita pelos arqueólogos) e de comunicação (expografia e ação educativo-cultural).

${ }^{23}$ Que pode ser realizada em etapas, à medida que as análises e as interpretações avancem, mas também deve alcançar as gerações futuras, além das presentes.

${ }^{24}$ Ver, a respeito, o excelente trabalho de Bonnot, 2014.

\begin{tabular}{|l|l|l|l|l|l|l|}
\hline (C) Rev. Arqueologia Pública & Campinas, SP & v.11 & n.2 & p. 196 & Novembro/2017 & ISSN 2237-8294
\end{tabular} 
Se por um lado o IPHAN não faz particular defesa dos processos de musealização, por outro, o IBRAM ainda não se debruçou de maneira mais acurada sobre as especificidades dos acervos arqueológicos, de forma que o que poderia ser uma área de convergência com muitos olhares atentos, revela uma lacuna nas políticas públicas patrimoniais: a Musealização da Arqueologia, com acervos produzidos por qualquer forma de pesquisa arqueológica, seja ela acadêmica ou preventiva ${ }^{25}$.

Esta área interdisciplinar entre a Arqueologia e a Museologia despontou com mais força no Brasil a partir da tese precursora de Maria Cristina Bruno (1999), a qual se seguiram diversos outros estudos, uma linha de pesquisa no Programa de Pós-Graduação em Arqueologia na Universidade de São Paulo, e outras iniciativas, como a criação da REMAAE, Rede de Museus e Acervos de Arqueologia e Etnologia, que mantém o nome original, mas na qual os diferentes agentes se nuclearam em torno das questões prementes da musealização da Arqueologia, gerando necessidade dos interessados em museus e acervos etnográficos e históricos buscarem a constituição de outras redes. A Musealização da Arqueologia:

\begin{abstract}
Organiza-se a partir de estudos relativos à cadeia operatória de procedimentos museológicos de salvaguarda (conservação e documentação) e comunicação (exposição e ação educativo-cultural), aplicados à realidade arqueológica, constituída a partir de referências patrimoniais, coleções e acervos. Por um lado, estes estudos buscam o gerenciamento e preservação destes bens patrimoniais e, por outro, têm a potencialidade de cultivar as noções de identidade e pertencimento (BRUNO, 2007, apud MORAES WICHERS, 2010, p. 47).
\end{abstract}

Cabe registrar o entendimento de que o acervo arqueológico em uma reserva técnica, mesmo com alguns artefatos selecionados para uma exposição "permanente", não está inserido nesta cadeia operatória museológica, que pressupõe, também, em paralelo, sua retomada por novas pesquisas e, ainda, cada vez mais frequentemente, a gestão compartilhada ou ao menos a participação em determinados momentos deste processo, que é contínuo, pelas populações do entorno de um museu. Portanto, os objetos fora da cadeia operatória museológica ou do processo de musealização têm uma sobrevida pálida em relação a todo seu potencial.

A Sociedade de Arqueologia Brasileira, na qual alguns simpósios sobre acervos arqueológicos já aconteceram, criou, mais recentemente, um Grupo de Trabalho sobre a

\footnotetext{
${ }^{25}$ Considera-se importante ressaltar, aqui, entretanto, que muitos trabalhos acadêmicos pósgraduados (de Especialização, de Mestrado e de Doutorado) têm aproveitado resultados das pesquisas arqueológicas preventivas para análises específicas voltadas à obtenção de títulos acadêmicos. Contudo, referências específicas sobre estes trabalhos não serão apresentadas neste artigo em razão de envolverem um número muito grande de casos.
} 
temática, que congrega profissionais das áreas de Arqueologia - predominantemente -, Conservação e Museologia, alguns com dupla formação, o que tem ventilado a discussão, especialmente com a realização do Fórum de Arqueologia da SAB - Acervos Arqueológicos, em Ouro Preto, de 26 a 28 de abril de 2017. O debate evidenciou um dos problemas do patrimônio arqueológico brasileiro como sendo que o momento da explosão quantitativa das pesquisas de Arqueologia Preventiva ocorreu em um cenário de fragilidade institucional dos museus. Entretanto, longe disso ter sido uma preocupação do campo da Arqueologia desde o início, aparentemente essa situação de fragilidade criava uma zona de conforto, conquanto o nível de exigência dos museus para receberem acervos era mínimo ou inexistente, ficando a cargo do arqueólogo definir quais contrapartidas julgava adequadas para o depósito dos acervos, dos quais se desresponsabilizava, assim como o empreendedor. Com a criação do IBRAM e notadamente do Estatuto dos Museus em 2009, o campo museal passou a ter uma regulação com exigências, como plano museológico (incluindo, aí, discussão sobre compatibilidade dos acervos com a política e missão do museu), equipe e infraestrutura adequadas, documentação museológica das coleções etc. Aparentemente, o ingresso dessas exigências e normas no cenário trouxe desconforto e desejo de encontrar outras saídas para o depósito dos acervos que não dependessem de seu atendimento, o que implicitamente está por trás da não adoção do termo "museu" ou do modelo de Musealização da Arqueologia daí por diante na maior parte dos projetos e relatórios de pesquisas arqueológicas que geraram acervos e, notadamente, por parte do IPHAN nas normas posteriores à criação do IBRAM.

\section{UM PROBLEMA CONTEMPORÂNEO: A CONSERVAÇÃO, A GESTÃo E A EXTROVERSÃO DO EXTENSO VOLUME DO ACERVO MATERIAL E DOCUMENTAL PRODUZIDO PELA ARQUEOLOGIA PREVENTIVA}

Como bem diz Darvill (2005), a Gestão de Recursos Arqueológicos não é mais o que costumava $\operatorname{ser}^{26}$, devido à crescente competição por escassos recursos financeiros e humanos num mundo cada vez mais preocupado com o "Maior", o "Melhor", o "Mais rápido", o "Mais", aliada à inevitável necessidade de decisões sobre o que resgatar dos vestígios arqueológicos das atividades humanas. Esse panorama significa que os arqueólogos não só têm de justificar sua própria existência e o trabalho a que se dedicam, mas também tomar decisões fundamentadas e justificáveis sobre o futuro dos materiais arqueológicos, por meio de julgamentos de "significância", "valor" e "importância" dos bens arqueológicos,

${ }^{26}$ Lembrando, aqui, que ele descreve a situação da arqueologia preventiva especificamente nos Estados Unidos da América.

\begin{tabular}{|l|l|l|l|l|l|l|}
\hline (C) Rev. Arqueologia Pública & Campinas, SP & v.11 & n.2 & p. 198 & Novembro/2017 & ISSN 2237-8294 \\
\hline
\end{tabular} 
num processo complexo e contínuo de valorização desses bens ${ }^{27}$, o que, em última instância, significa decidir quais testemunhos materiais da história humana devem ou não ser salvos da destruição e guardado para as gerações presentes e futuras.

Em suma, é importante ressaltar, aqui, que a responsabilidade do arqueólogo e dos órgãos de proteção ao patrimônio arqueológico - o IPHAN, no caso do Brasil - é enorme, estando estes atores sujeitos a todo tipo de contestação e discussão, já que o processo decisório não pode ser outorgado a outrem no processo de Avaliação Ambiental de empreendimentos potencialmente destruidores do patrimônio arqueológico nacional, localizados ou regionalizados. Fica a cargo dos pesquisadores permissionários executar os projetos de pesquisa arqueológica preventiva, e do órgão que outorgou, em confiança, a responsabilidade a estes arqueólogos, a difícil decisão sobre o que estudar e o que $\operatorname{preservar}^{28}$. Afinal, como já se reconhece há pelo menos um quarto de século, a significância arqueológica é uma qualidade mutável (BOWDLER, 1984), dependente da época ou do local onde as pesquisas arqueológicas vão ser ou estão sendo realizadas. $O$ único espaço real para a discussão das conclusões das pesquisas preventivas realizadas no processo de licenciamento ambiental de empreendimentos que causam, em menor ou maior grau, alterações ambientais que afetam os bens arqueológicos são as audiências públicas, organizadas pelo IBAMA ao final dos Estudos de Impacto Ambiental, seja em cumprimento à legislação vigente, seja por demanda de órgãos e comunidades específicas das áreas afetadas pelos empreendimentos em avaliação.

A legislação brasileira está atenta a dois aspectos importantes dessa tarefa: a produção e divulgação do conhecimento científico e a educação patrimonial. Considerando que estes fazeres ocorrem no presente e o acervo gerado se torna patrimônio permanente, verifica-se que é ainda lacunar a faceta da musealização da arqueologia, que estaria comprometida com o futuro dos acervos arqueológicos e com os dados a eles relacionados, por consistir na esfera apropriada à garantia de uma dinâmica de contínua produção de conhecimento e extroversão, que a realização das ações de educação patrimonial, mais imediatas, não possibilitam no longo prazo.

A musealização relaciona-se com "o destino das coisas", nas palavras de Bruno (2009). Neste sentido, o patrimônio arqueológico tem na musealização da arqueologia a perspectiva de conexão com as gerações futuras, na mesma medida em que a educação patrimonial dialoga com a geração do presente. A Museologia tem um compromisso com a herança patrimonial em longo prazo que deve ser considerado, em se tratando de recursos

${ }^{27}$ Ver, a respeito da problemática da "valorização" de bens arqueológicos, Carman, 2002.

${ }^{28}$ Merece ser reafirmado, aqui, que o primeiro axioma da gestão de recursos arqueológicos, como bem lembra Carman, 2002, é o de que os vestígios do passado são finitos e não renováveis.

\begin{tabular}{|l|c|c|c|c|c|c|}
\hline (C) Rev. Arqueologia Pública & Campinas, SP & v.11 & n.2 & p. 199 & Novembro/2017 & ISSN 2237-8294 \\
\hline
\end{tabular} 
culturais não renováveis, pertencentes a todos os cidadãos de uma Nação e não somente àqueles que possam ser alcançados por trabalhos de extroversão realizados em um curto espaço de tempo.

Essa perspectiva alinha-se com muitas outras, como afirma Ruiz (2013), ao ressaltar a necessidade de pensar o museu não somente como depósito de materiais e centro de pesquisa destinado a especialistas, mas como um centro de projeção cultural e social ligado ao processo de construção identitária. Para tal, remete à Declaração da Cidade de Salvador, resultante do I Encontro Ibero-Americano de Museus, que, entre suas diretrizes, propõe "assegurar que os museus sejam territórios de salvaguarda e difusão de valores democráticos e de cidadania, colocados a serviço da sociedade, com o objetivo de propiciar o fortalecimento e a manifestação das identidades, a percepção crítica e reflexiva da realidade, a produção de conhecimentos, a promoção da dignidade humana e oportunidades de lazer" ${ }^{29}$.

Assinala-se, aqui, que estes são compromissos dos museus, que estão organizados em vários níveis, com códigos de ética e legislação próprios, como o Código de Ética do Conselho Internacional de Museus (ICOM), e, no caso do Estatuto de Museus, com a legislação e o código de ética relativos ao profissional museólogo. Não é o caso, por exemplo, de outros modelos institucionais ou soluções pouco delineadas, como os memoriais (quando são compreendidos como museus) ou reservas técnicas simplesmente, sobre os quais não recaem normas ou mesmo um esforço de conceituação. Dessa forma, quando a legislação específica sobre licenciamento ambiental sugere um tratamento mínimo e este mínimo é atrelado a formatos de guarda que não têm compromisso claro com o futuro dos acervos, perde-se um enorme potencial não só de sua conservação adequada às mais modernas normas museológicas, como também de sua reinterpretação e reapropriação, a longo prazo, por outros cientistas e pelas futuras gerações. Somente a lógica do processo de musealização pode lançar perspectivas para o destino do material proveniente das pesquisas arqueológicas:

O processo de musealização ocorre a partir de uma seleção e atribuição de sentidos feitas dentro de um universo patrimonial amplo, resultando em um recorte formado por um conjunto de indicadores da memória ou referências patrimoniais tangíveis ou intangíveis, naturais ou artificiais, indistintamente. Feita a seleção, essas referências patrimoniais ingressam em uma cadeia operatória que corresponde ao universo de aplicação da Museologia museografia. [...] A cadeia operatória representa tanto a responsabilidade pela herança constituída para o futuro, como a comunicação permanente e

${ }^{29}$ Declaração da Cidade de Salvador. I Encontro Ibero-Americano de Museus, 2007. Disponível em: <http://www2.cultura.gov.br/upload/Carta\%20de\%20Salvador\%202007_1183495707.pdf> (acesso em: outubro de 2015). 
processual [...].

A preservação, ou processo de musealização, abrange desde a seleção das referências patrimoniais à devolução para a sociedade, que por sua vez produz novos bens patrimoniais e interfere em novas seleções e atribuições de sentido, em modo contínuo. (DUARTE CÂNDIDO, 2014, p. 154).

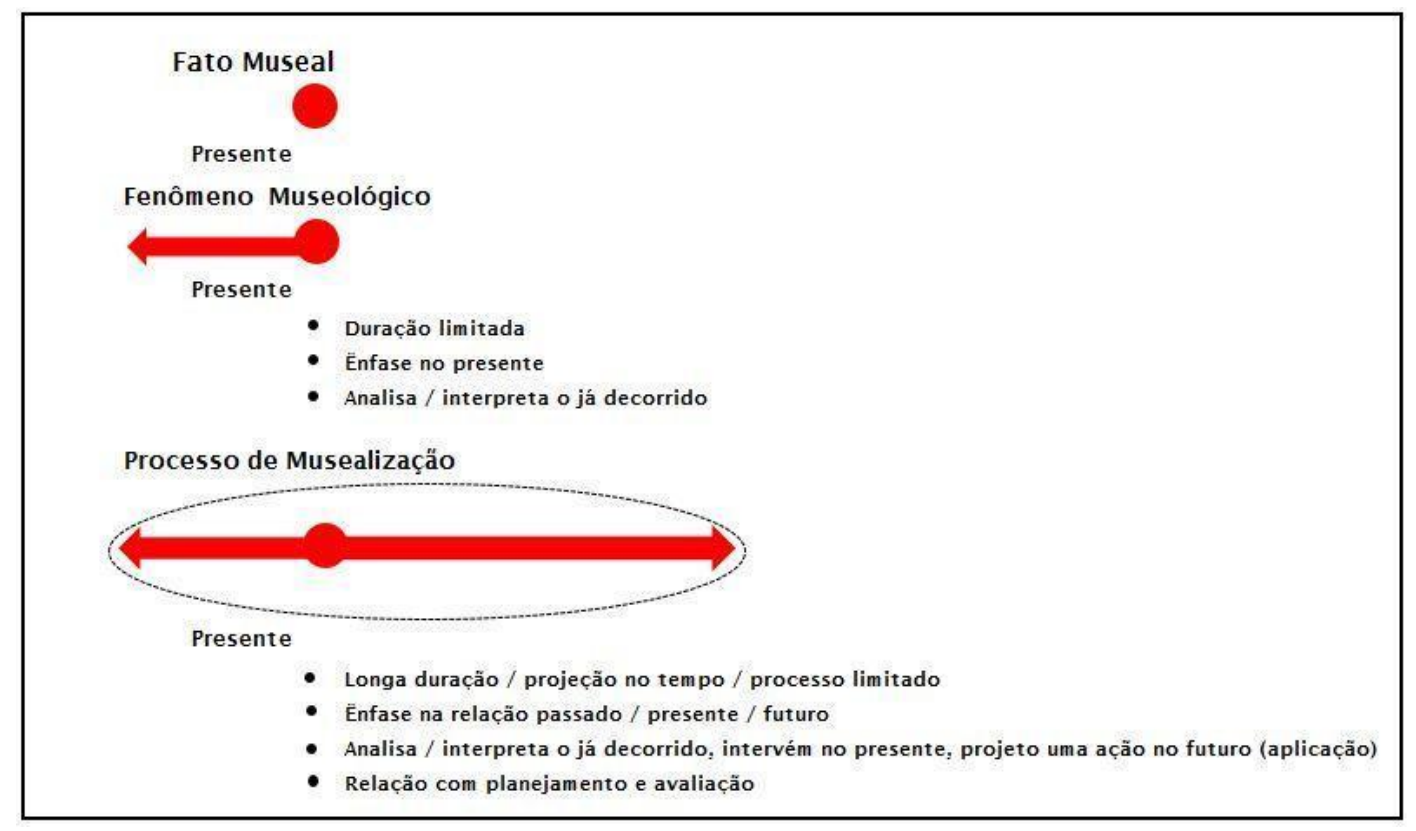

Figura 4. Fato Museal/Fenômeno Museológico/Processo de Musealização (Fonte: DUARTE CÂNDIDO, 2014, p. 61).

A preservação do patrimônio arqueológico é historicamente marcada por rotas de desterritorialização e transferências patrimoniais monumentais, mantendo nos centros do poder as coisas e a posse do saber sobre as coisas (BRUNO, 1999). Os processos de musealização, não importa de que tipo de referências patrimoniais, raramente escapam dessa lógica de desterritorialização e concentração, tônica dos grandes museus nacionais existentes em quase todo o mundo ocidental. Entretanto, a Arqueologia apresenta desafios específicos que vão desde a intensa conexão entre os artefatos e seu contexto, seja de produção ou de descarte, à impossível mobilidade de alguns deles - edificações, registros rupestres, entre outros -, levando a uma necessária reflexão sobre a grande aderência entre patrimônio arqueológico e território, até mesmo porque os sítios arqueológicos não constituem entidades isoladas, mas interagem espacialmente com outros sítios arqueológicos, não apenas funcionalmente, mas também socialmente, já que, a não ser em caso de catástrofes, não existem sociedades humanas isoladas.

Não por acaso, duas situações costumam ocorrer: 
a) processos de musealização envolvendo sítios arqueológicos em áreas habitadas contemporaneamente, que costumam envolver a população e transitar entre conceitos de museu de território e ecomuseu ${ }^{30}$;

b) ecomuseus e museus de território, que frequentemente têm o patrimônio arqueológico de diferentes temporalidades incorporado ${ }^{31}$ como acervo operacional ou institucional ${ }^{32}$.

É precisamente na relação com os diferentes grupos da população que mais se diferenciam os museus ou processos de musealização dos demais tipos de instituição de guarda. Por definição, o museu tem este compromisso, já que constitui "instituição sem fins lucrativos, permanente, a serviço da sociedade e de seu desenvolvimento e aberta ao público, que adquire, conserva, pesquisa, divulga e expõe o patrimônio tangível e intangível da humanidade e seu meio ambiente para fins de educação, estudo e divertimento" (ICOM, 2007, grifos nossos).

Assim, o museu tem a dupla função de estar aberto para a comunidade científica e também para aquelas referenciadas em suas coleções ou seus descendentes, além das populações do entorno próximo ou distante, no tempo e no espaço. Em relação à comunidade científica, cabe ressaltar a relevância da abertura dos acervos para novas interpretações, olhares e preocupações, pois nascidos para serem pragmáticos, os museus são dialéticos, celebrando o passado, mas voltados a uma interpretação mediante um olhar do presente, sendo isto o que torna os museus tão interessantes e instigantes (CHAGAS, comunicação verbal, apud DUARTE CÂNDIDO, 2014, p. 43).

Considerando-se a premissa da opção pela musealização, existem diferentes possibilidades, havendo, no entanto, uma conexão com o território e com as populações do entorno dos sítios que é preciso considerar, mesmo quando estas populações não foram as originalmente responsáveis pela formação do registro arqueológico ou por pelo menos uma de suas etapas de uso e reapropriação ${ }^{33}$.

${ }^{30}$ Exemplo do Museu do Alto Sertão da Bahia (MASB), da Vila Museu e Campo Arqueológico de Mértola (Portugal), e do Parque Cultural Maestrazgo, na Espanha. A este respeito, ver também Ruiz (2013).

${ }^{31}$ Exemplo do Ecomuseu do Seixal e do Musée Dauphinois em Grenoble, França, entre outros.

32 Acervo institucional é aquele constituído por coleções sistemáticas de objetos móveis que compõem a coleção registrada formalmente pelo museu em virtude de seu caráter documental. Além do acervo institucional, os museus podem trabalhar com outras referências patrimoniais não literalmente incorporadas ao seu acervo, denominadas acervo operacional. Ele pode ser constituído por espaços, paisagens, estruturas, monumentos, equipamentos, manifestações culturais, saberes e fazeres socialmente apropriados (BEZERRA DE MENEZES, 1985; OLIVEIRA, 2002; SANTOS, 2014).

${ }^{33}$ Há que se considerar que o próprio processo de musealização, assim como a pesquisa arqueológica, são também contextos sucessivos de apropriação real e simbólica dos vestígios.

\begin{tabular}{|l|c|c|c|c|c|c|}
\hline (C) Rev. Arqueologia Pública & Campinas, SP & v.11 & n.2 & p. 202 & Novembro/2017 & ISSN 2237-8294 \\
\hline
\end{tabular} 
A tradição de desterritorialização, que gerou por séculos memórias exiladas (BRUNO, 2005), não é mais considerada um modelo adequado de incorporação das fontes arqueológicas ao patrimônio; ao contrário, é reputada como uma das responsáveis pela formação de uma "estratigrafia do abandono" (idem). Assim, para além do modelo de constituição de grandes museus nos centros de poder, como as capitais, a Arqueologia aponta para a formação de centros regionais mais próximos do local de origem dos artefatos, onde eles possam ser interpretados em contexto paisagístico ${ }^{34}$, sem descartar a fruição das coleções e dos dados por interessados nos criativos processos adaptativos das sociedades humanas aos mais diversos ambientes, reflexos da criatividade cultural desta espécie.

Grande parte dos acervos arqueológicos no Brasil está abrigado em instituições não especializadas em Arqueologia, das mais diversas tipologias, em geral museus regionais e municipais, sendo estes a vinculação administrativa mais frequente no país, cerca de $41 \%$ (IBRAM, 2010). Muitos museus de Arqueologia no Brasil se encontram nas universidades públicas e privadas, havendo acervos arqueológicos importantes nos museus mais antigos do País, como o Museu Nacional da UFRJ (Rio de Janeiro) e o Museu Paraense Emílio Goeldi (Belém).

Nem todos os museus que possuem acervos arqueológicos, no entanto, possuem profissionais com formação na área ou mantêm a realização de pesquisas arqueológicas, não sendo, contudo, este o caso dos dois museus acima citados, onde pesquisa e musealização ocorrem há muito tempo, constituindo-se, eles, exemplos de instituições em que pesquisa e musealização se entrelaçam.

No entanto, essa não é a realidade mais comum no País, onde, ao mesmo tempo em que se avolumam as pesquisas de Arqueologia Preventiva e, em consequência, os acervos por elas gerados, estes na maioria das vezes não passam nem por processos de musealização nem se encontram disponíveis para reinterpretações, até mesmo porque muitas vezes não possuem documentação associada que permita boa contextualização e, portanto, prestem-se às tão necessárias reanálises, uma vez que a Arqueologia não é uma ciência exata, mas uma ciência humana que se beneficia de novas teorias e de novos olhares, antenados com os mais diversos interessados e com os novos tempos.

A guarda dos acervos gerados pela Arqueologia Preventiva em núcleos regionais ou locais, no momento, não tem sido decidida pela lógica das dimensões territoriais dos empreendimentos cujo licenciamento ambiental levam às pesquisas arqueológicas inseridas nos processos de avaliação ambiental. Seria importante, a médio e longo prazo, pensar na

${ }^{34}$ Sobre a importante inter-relação entre arqueologia e paisagem, ver Wagstaff, 1987; Sousa, 2005.

\begin{tabular}{|l|l|l|l|l|l|l|}
\hline (C) Rev. Arqueologia Pública & Campinas, SP & v.11 & n.2 & p. 203 & Novembro/2017 & ISSN 2237-8294 \\
\hline
\end{tabular} 
implantação, quando eles não existirem, de museus regionais que guardem acervos procedentes de pesquisas com um viés regional, como, por exemplo, bacias e sub-bacias hidrográficas, onde pesquisas arqueológicas se fizeram, se fazem e continuarão a ser feitas, buscando a compreensão da ocupação de vastos territórios, com um elo paisagístico entre eles, razão pela qual foram mencionadas as bacias e sub-bacias hidrográficas. Afinal:

as bacias hidrográficas constituem elementos naturais privilegiados nos
deslocamentos e expansões regionais de populações indígenas pré-
coloniais e também do conquistador europeu no período colonial, seu
recorte é altamente favorável à formulação de: problemáticas sobre a
ocupação humana pretérita da área de estudo; definição de territórios de
captação de diferentes recursos para sociedades com tecnologia simples e
formulação de modelos preditivos sobre a localização e funcionalidade de
assentamentos humanos pretéritos.
(CALDARELLI, 2012).

Museus de capitais estaduais têm maior possibilidade de cumprir o papel de museus regionais, embora não se exclua, aqui, que museus bem estruturados, em municípios com bom equipamento urbano, possam exercer esse papel, mesmo não estando localizados em capitais.

Quanto aos museus locais (tenham eles esta denominação ou qualquer outra similar, como museus municipais e casas de memória) ${ }^{35}$, é preciso reconhecer que existe sempre o desafio do acesso de maior público ao patrimônio arqueológico neles depositado ${ }^{36}$.

Um canal para viabilizar este acesso é a via digital. $\mathrm{Na}$ realidade, exposições virtuais, sejam em que contexto for, aparecem como panaceia e solução incontornável na atualidade, por permitirem a fruição dos acervos, temporária ou permanentemente, a longa distância, pelos mais diversos públicos interessados. É preciso enfatizar, no entanto, o debate sobre a adequação do uso do virtual como algo imaterial, quando a informação desses museus ocupa espaço (digital), recursos humanos e financeiros para suas operações, mesmo que possam ser infinitamente menores que aqueles empregados na implantação de um museu real (analógico?). O termo "virtual" encerra a ideia de um potencial a ser realizado, devendo-se mencionar aqui que alguns autores alertam para a necessidade de não confundir o museu virtual - ou as exposições virtuais disponibilizadas por museus físicos - com o uso de substitutos ou de imagens digitais (DELOCHE, 2002; CUNHA, 2012).

${ }^{35}$ Não se está pensando, no presente artigo, em museus de arte, mas em museus históricos e arqueológicos, que são os que se coadunam com a guarda e extroversão de acervos arqueológicos.

${ }^{36}$ Exceto em caso de museus municipais situados em capitais estaduais.

\begin{tabular}{|l|l|l|l|l|l|l}
\hline (C) Rev. Arqueologia Pública & Campinas, SP & v.11 & n.2 & p. 204 & Novembro/2017 & ISSN 2237-8294 \\
\hline
\end{tabular} 
Para além dessa discussão, é possível enxergar nos museus digitais ou cyber museus as vantagens de superação de algumas limitações: "No contexto digital, temos a oportunidade e possibilidade de tentar resolver questões inerentes aos limites materiais espaciais das nossas instituições museológicas, como, por exemplo, no que diz respeito à capacidade de receber, assimilar e atender a uma grande quantidade e diversidade de públicos" (CUNHA, 2002, p. 246). Em se tratando de aspectos já indicados neste texto, como a dificuldade de acesso a alguns territórios onde se encontram os sítios e acervos arqueológicos, o recurso do museu digital permite facilitar o acesso para interessados de qualquer lugar, além de possibilitar reconstituições de contextos não afetadas pelos dilemas da ética da restauração ou preocupações com reversibilidade e compatibilidade de materiais, entre outras. Permite, ainda, mesmo requerendo as devidas autorizações, reunir em um ambiente digital itens do patrimônio arqueológico que estejam dispersos em diferentes museus e territórios. Exposições assim organizadas podem ainda minimizar os efeitos da perda de sítios arqueológicos - ou de algumas camadas estratigráficas -, quando isto for inevitável.

Ainda que o museu físico seja o local privilegiado por excelência para guarda e fruição do material procedente das pesquisas arqueológicas e que a experiência do contato com o objeto museológico seja singular, é imprescindível que se utilizem todos os recursos que a tecnologia da atualidade oferece para qualificar as iniciativas de preservação e, especialmente, o acesso ao público dos resultados das pesquisas arqueológicas, desde a confecção de réplicas, por meio de impressão em 3D, de objetos que normalmente não ficam disponíveis para manipulação - por sua fragilidade ou por sua raridade -, até a criação de museus e exposições em formato digital.

Por outro lado, essa acessibilidade que parece ilimitada requer cuidados, especialmente com a transposição de mídias que se tornam rapidamente obsoletas para outras mais atualizadas:

Os museus digitais podem constituir-se como locais privilegiados, pois determinados suportes documentais podem ter o seu tempo de vida aumentado, quando processados digitalmente e depositados em arquivos. No entanto, é importante que tenhamos consciência de que quando estamos falando de arquivos e suportes digitais também existem vulnerabilidades e riscos de perda, como a corrupção de dados ou a incompatibilidade de leituras dos mesmos devido ao rápido avanço das tecnologias de registro e leitura, ou ainda dos sistemas de diálogo entre usuário. Este fator nos obriga a pensar nossos fundos digitais na perspectiva de que devem passar por permanente atualização (...). (CUNHA, 2012, p. 243). 
Dentre as responsabilidades que os órgãos de proteção ao patrimônio arqueológico, os arqueólogos, os curadores e todos os profissionais envolvidos no processo da pesquisa arqueológica voltada ao licenciamento ambiental de empreendimentos que alteram as condições ambientais dos locais, mais ou menos extensos, onde sua implantação é avaliada, incluindo todos os ambientes que permitem ao arqueólogo buscar as respostas sobre as razões de os sítios arqueológicos se encontrarem onde se encontram e apresentar as características que atualmente apresentam, está a de produzir bons dados e assegurar sua preservação, a longo prazo.

Está mais que estabelecido, hoje, que a preservação dos dados, a acessibilidade a eles e a troca das informações geradas pela arqueologia preventiva são uma obrigação dos pesquisadores e dos órgãos responsáveis por esse trabalho e fazem parte do processo de gestão dos bens arqueológicos (McMANAMON; BARNES; STOUT, 2008), e a digitalização dos acervos e dos dados procedentes dos projetos de arqueologia é a única maneira de se assegurar isso na atualidade (KINTIGH, 2006; McMANAMON; KINTIGH, 2010). Vale ressaltar que o CNA/DEPAM/IPHAN tem reiteradamente solicitado os dados digitalizados das pesquisas arqueológicas, inclusive com shapes de todas as informações mapeáveis, desde a publicação da Instrução Normativa IPHAN 01/2015.

No entanto, um grande desafio coloca-se por trás do processo de digitalização das coleções e documentos: a dinâmica da transformação das mídias digitais empregadas nesse processo, em que a superação de mídias antigas por mídias novas é cada vez mais frequente, tornando rapidamente obsoletos arquivos digitalizados em mídias mais antigas, o que é um dos mais importantes problemas a serem equacionados, no que concerne ao tema abordado no presente artigo.

Na obra seminal de Conway (2001), logo no prefácio, coloca-se o ingente problema que aqui se quer discutir:

Este texto estabelece uma reflexão cujo objetivo é centralizar os conceitos e princípios da ética da preservação no crescente contexto da informação digital. Isto compreende uma estrutura para o gerenciamento e planejamento para preservação a partir de duas perspectivas: os contextos 1) e as prioridades 2) para a ação, indicando similaridades e diferenças entre a prática atual e as necessidades futuras. Isto sugere que muitos princípios de gerenciamento em preservação podem ser aplicados em um grande número de contextos tecnológicos, mas que alguns outros, já amplamente estabelecidos, não podem mais ser adotados. (Commission on Preservation \& Access, 2001).

Não há mais como discutir e implementar processos de conservação de acervos materiais e documentais procedentes de pesquisas arqueológicas - preventivas ou não sem pensar na necessidade de periodicamente atualizar os arquivos digitalizados tanto dos 
objetos constituintes do acervo de cultura material quanto dos documentos de campo, de laboratório e de disseminação dos resultados. Como diz o autor supracitado, "o universo digital transforma os conceitos da preservação tradicional: em vez de garantir a integridade física do objeto, passa a especificar a geração e a manutenção do objeto cuja integridade intelectual é sua característica principal" (CONWAY, 2001, p. 12).

É aqui que, no processo de licenciamento ambiental, a atuação dos órgãos que nele operam se torna vital - IBAMA, em todo o processo, e IPHAN, no que concerne ao patrimônio arqueológico, histórico e cultural especificamente ${ }^{37}$. O interesse especial recai na Licença de Operação, que autoriza o interessado em um determinado empreendimento a iniciar suas atividades. Segundo a Cartilha de Licenciamento Ambiental publicada pelo Tribunal de Contas da União (TCU), tal licença, após o cumprimento comprovado de todos os requisitos das licenças ambientais anteriores - Licença Prévia (LP) e Licença de Instalação (LI) -, e a partir da aprovação da proposta de convívio do empreendimento com o meio ambiente, estabelece condicionantes para a continuidade da operação.

No Brasil, a concessão da Licença de Operação, que deve ser requerida pelo empreendedor com antecedência mínima de 120 dias, é por tempo finito: "A licença não tem caráter definitivo e, portanto, sujeita o empreendedor à renovação, com condicionantes supervenientes. O prazo de validade da licença de operação deverá considerar os planos de controle ambiental e será, em regra, de, no mínimo, quatro anos e, no máximo, dez anos"38. Portanto, a renovação da Licença de Operação (LO) é obrigatória, devendo o empreendedor solicitá-la com antecedência mínima de 120 dias do prazo de sua expiração, comprovando que o desempenho ambiental do empreendimento está em conformidade com o compromisso firmado para a obtenção da LO, inclusive quanto à boa aplicação das medidas de controle ambiental.

Qualquer modificação posterior pretendida pelo empreendedor, como a ampliação da área de influência do empreendimento (o que tem repercussões práticas sobre os bens arqueológicos) deverá ser informada ao órgão ambiental (ou seja, no caso de empreendimentos federais, ao IBAMA), que também é encarregado de monitorar os empreendimentos em operação, o que, no caso de verificar impactos ambientais não

${ }^{37}$ Embora o propósito do presente artigo seja o patrimônio arqueológico, o que se diz a partir de agora se aplica também aos documentos escritos, cartográficos, fotográficos e videográficos produzidos no processo de registro do patrimônio histórico e cultural; neste último caso, em especial as manifestações culturais imateriais, cuja duração não se pode prever num mundo em constante transformação, as quais muitas vezes são filmadas em mídias que certamente estarão ultrapassadas em poucos anos.

${ }^{38}$ Fonte: <http://portal2.tcu.gov.br/portal/pls/portal/docs/2059156.PDF>. Acesso em: novembro, 2015.

\begin{tabular}{|l|l|l|l|l|l|l|}
\hline (c) Rev. Arqueologia Pública & Campinas, SP & v.11 & n.2 & p. 207 & Novembro/2017 & ISSN 2237-8294
\end{tabular} 
previstos ou mal gerenciados pelo empreendedor, poderá exigir novas condicionantes para a renovação da Licença de Operação.

É na Licença de Operação e em sua necessária renovação que o IPHAN pode atuar para assegurar que os registros digitalizados dos materiais arqueológicos e das documentações de campo e de laboratório, escritas ou visuais, sejam assegurados pelo empreendedor nas seguintes etapas:

- Como condicionante para a Licença de Operação - assegurar a digitalização de todo o acervo material e documental (escrito e visual) nas mais modernas mídias disponíveis no momento, inclusive com a entrega dos aparelhos necessários à(s) instituição(ões) que ficaram com a responsabilidade de guardar o(s) acervo(s) produzido(s);

- Como condicionante das renovações da Licença de Operação - assegurar a transformação de todo o material digitalizado para as novas mídias advindas durante a concessão inicial da LO e data de sua renovação, impedindo, assim, sua obsolescência e assegurando que esse patrimônio cultural retirado de seu local de origem estará efetivamente disponível para as gerações futuras, que também são suas herdeiras.

O mesmo processo deve assegurar o processo de musealização, garantindo continuidade da extroversão da informação original sobre o acervo e das novas informações advindas das interpretações sobre o material cultural e os demais materiais a ele associados (orgânicos ou minerais, de relevância para a interpretação dos dados arqueológicos), após a concessão da LO original. Ou seja, este é um compromisso que deve ser assumido contínua e dinamicamente pelo empreendedor, enquanto o empreendimento operar; até sua desativação.

No licenciamento ambiental no Brasil, a transferência de um sistema digital para outro mais avançado poderia ser feita sempre que um empreendimento solicitasse a renovação da Licença de Operação, que ocorre em intervalos distintos (variando entre 4 e 10 anos).

Em todos os formatos anteriormente indicados, é imprescindível a preservação conjunta dos documentos em diferentes suportes que são produzidos durante a pesquisa arqueológica, inclusive porque só a partir deles é possível "refazer" partes da pesquisa, já que ela envolve a destruição dos sítios.

Tem-se consciência de que informação é poder, e sendo o patrimônio arqueológico no Brasil assegurado como direito de todos os cidadãos brasileiros, a informação 
arqueológica precisa ser partilhada: tanto os acervos e sítios arqueológicos quanto o acervo documental gerado pelas pesquisas.

Nesse sentido, Silva e Lima (2007, p. 282) lembram que o conceito de registro arqueológico compreende tanto as evidências físicas - artefatos e ecofatos - recuperadas em uma intervenção em sítio arqueológico quanto registros documentais produzidos antes, durante e após esta intervenção, considerados também como registros primários. "O registro arqueológico constitui, portanto, a base de dados sobre a qual opera a arqueologia", apontam. Entretanto, são conhecidas práticas de restrição do acesso a estas informações, nos quais o registro arqueológico é tratado como commodities (LOCK apud FORD, 2010), algo que precisa ser equacionado especialmente no Brasil, em concordância com a legislação que atribui valor de patrimônio nacional aos bens arqueológicos.

As autoras acima referidas advogam "por uma política de preservação dos registros documentais de arqueologia", que garanta a guarda das informações de contexto juntamente às do acervo arqueológico, não só normatizando os futuros depósitos mas também atuando sobre o passivo, no que for ainda possível recuperar. Além disso, lembramos a necessidade de que esses acervos possam ser livremente pesquisados por profissionais que não sejam somente da equipe que realizou inicialmente a pesquisa, ou pertencentes à instituição de guarda, abrindo-os a novas análises e interpretações, por diferentes pontos de vista.

Cabe assinalar que a preocupação com lacunas na gestão dos dados primários da pesquisa científica no Brasil, não só no que diz respeito à Arqueologia, tem preocupado o Instituto Brasileiro de Museus, que em diálogo com o Ministério da Educação, CNPq e Capes, tem buscado delinear propostas para melhor equacionamento da questão por meio da elaboração de políticas públicas concernentes. Todos os campos do saber estão em constante transformação e é imperativo garantir a possibilidade de retorno às fontes e reinterpretações como parte do fazer científico. No caso específico da Arqueologia, esta necessidade culmina com o fato de tratar-se de recursos culturais não-renováveis, impactados pela própria pesquisa, que não pode ser retomada, a não ser por meio de fontes secundárias e do que é preservado como vestígio.

\section{CONSIDERAÇÕES FINAIS}

A gestão dos acervos arqueológicos e a disseminação da informação produzida, assim como a possibilidade de reanálise desta informação por parte das comunidades e pesquisadores interessados tanto do presente quanto do futuro são partes importantes do processo de gestão de bens culturais, ao qual se liga a pesquisa arqueológica preventiva. 


\section{Revista de Arqueologia Pública}

Conforme McManamon; Barnes e Stout $(2008)^{39}$, a gestão abrange coleções arqueológicas, registros, relatórios e dados eletrônicos, os quais precisam ser pensados em termos de preservação e acesso em longo prazo. Para isso, é preciso ter sempre presente a necessidade de desenvolvimento e adoção de técnicas e processos que permitam a contínua transformação dos dados - aí compreendidos o acervo material, os registros escritos e as imagens digitalizadas -, em compasso com os novos desenvolvimentos tecnológicos.

Esta perspectiva já foi bem expressa por Martinez (2006), ao apontar as bases teóricas de sua proposta, esposada pelas autoras deste artigo: batalhar pelo desenvolvimento de uma Arqueologia Preventiva "que intenta superar dicotomías que paralizan tanto el conocimiento como la acción y que permite una gestión del patrimonio arqueológico integrada en la práctica discursiva del sistema pero que apunta más allá de sus condicionantes inmediatos".

Se este artigo conseguir que pesquisadores, gestores e os diversos profissionais do campo do patrimônio preocupem-se com essa causa e procurem meios de avançar nas propostas apresentadas, os objetivos das autoras já terão sido alcançados.

\section{REFERÊNCIAS BIBLIOGRÁFICAS}

ARAÚJO COSTA, Fernanda. Projeto Baixo Tocantins: Salvamento Arqueológico na Região de Tucuruí. Dissertação de Mestrados, FFLCH-USP, 1983.

ARAÚJO-COSTA, Fernanda; CALDARELLI, Solange B. (Org.). Programa de Estudos Arqueológicos na Área do Reservatório de Kararaô (PA) - Relatório Viabilidade. Belém, MPEG, 2 vol., 1988.

BEZERRA DE MENEZES, U. T. Cultura e Cidade. In: Revista Brasileira de História, São Paulo, 5, 1985: 197-205.

BONNOT, Thierry. L'Attachement aux choses. Paris, CNRS Éditions, 2014.

BOWDLER, Sharon. Archaeological significance as a mutable quality. In: SULLIVAN, Sharon; Sandra BOWDLER (Ed.), Site surveys and assessments in Australian Archaeology. Canberra, Dept. of Prehistoria, Research School of Pacific Studies, The Australian National Univ., 1984.

${ }^{39}$ É importante apontar, aqui, também o relevante artigo de McManamon (2010) sobre este assunto. \begin{tabular}{l|l|l|l|l|l|l|}
\hline (c) Rev. Arqueologia Pública & Campinas, SP & v.11 & n.2 & p. 210 & Novembro/2017 & ISSN 2237-8294
\end{tabular} 
BRUNO, Cristina. Estudos de cultura material e coleções museológicas: avanços, retrocessos e desafios. In: GRANATO, Marcus; RANGEL, Márcio F. (Orgs.) Cultura material e patrimônio da ciência e tecnologia. Rio de Janeiro: Museu de Astronomia e Ciências Afins - MAST, 2009. p. 14-25. (Livro eletrônico).

BRUNO, M. Cristina O.. Musealização da Arqueologia: um estudo de modelos para o Projeto Paranapanema. Lisboa: Universidade Lusófona de Humanidades e Tecnologias, 1999 (Cadernos de Sociomuseologia, 17).

CALDARELLI, Solange B. O Patrimônio Arqueológico na Avaliação Ambiental Integrada de Bacias Hidrográficas. Trabalho apresentado no $1^{\circ}$ Congresso Brasileiro de Avaliação de Impacto/2a conferência da REDE de Língua Portuguesa de Avaliação de Impactos. Disponível em: <http://avaliacaodeimpacto.org.br/wp-content/uploads/ 2012/10/027_ Arqueologia_AAl-de-BaciasHidrográficas_Texto.pdf $>$.

CALDARELLI, Solange B. Arqueologia Preventiva: uma disciplina na confluência da Arqueologia Pública e da avaliação ambiental. Goiânia, Revista Habitus, v. 14, n. 1, p. 0530, jan./jun. 2015.

CALDARELLI, Solange B.; SANTOS, Maria do Carmo Mattos Monteiro dos, Arqueologia de Contrato no Brasil. São Paulo, Revista USP, 44: 52-73, 2000.

CALDERÓN DE LA VARA, V.; Y. JÁCOME e I. SOARES. Relatório do Projeto Sobradinho de Salvamento Arqueológico, Salvador, Convênio CHESF/A.A.P.H.BA, 1977.

CARMAN, John. The value "Debate" in Archaeology. In: CARMAN, John, Archaeology \& Heritage: An Introduction. London, New York, 2002: 148-185.

CHMYZ, Igor. As realidades políticas e sociais da arqueologia de salvamento no Brasil. Arqueologia, 5: 1-15, 1985.

COMMISSION ON PRESERVATION \& ACCESS. Prefácio para a Edição Americana. In: CONWAY, Paul, Preservação no universo digital. Rio de Janeiro, Projeto Conservação Preventiva em Bibliotecas e Arquivos. 2001.

CUNHA, Marcelo Nascimento Bernardo da. "Algumas considerações sobre museus digitais". In: SANSONE, Lívio (Org.). A política do intangível: museus e patrimônios em nova perspectiva. Salvador: Edufba, 2012. 


\section{Revista de Arqueologia Pública}

DANS, Eva $P$. The analysis of an emerging sector: comercial archaeology and its rising and development from the sectoral system of innovation. PhD Thesis Outline. Heritage Laboratory, Spanish Council for Scientific Research, 2010.

DELOCHE, Bernard. El museo virtual. Gijón: Ediciones Trea, 2002.

DEMOULE, Jean Paul. “Rescue Archaeology: A European View”. In: Annual Review of Anthropology, v. 41: 611-626, 2012.

DUARTE CÂNDIDO, Manuelina Maria. Gestão de museus, um desafio contemporâneo: diagnóstico museológico e planejamento. (2a ed.) Porto Alegre: Medianiz, 2014.

DUARTE CÂNDIDO, Manuelina Maria. "Gestão do patrimônio arqueológico no centro-oeste: contribuições para a Rede de Museus e Acervos de Arqueologia e Etnologia (REMAAE)". In: Revista de Arqueologia da Sociedade de Arqueologia Brasileira, SAB, vol. 26 n. 022013 + vol. 27 n. 012014 , p. 132-140.

EVERILL, Paul. The Invisible Diggers: A Study of British Commercial Archaeology. Oxford, Oxbow Books, 2009.

FORD, Matt. "Hidden treasure" In: Nature, Vol 464|8 April 2010.

GEERTZ, C. The Interpretation of Cultures. Basic Books, New York, 2000.

GOULART, Marilandi. Projeto Salvamento Arqueológico do Uruguai, Vols. I/II. Itajaí: UNIVALI, 1997.

INSTITUTO BRASILEIRO DE MUSEUS [IBRAM]. Museus em Números. Brasília: Instituto Brasileiro de Museus, 2011.

JOHANSSON, N.; L. G. JOHANSSON, Rescue Archaeology. In: D. L. HARDESTY (Ed.), Archaeology, v. 2. UNESCO/EOLSS, 2001. Disponível em: <http://www.eolss.net/samplechapters/c04/E6-21-04-04.pdf>. Acesso em: outubro/2015.

KERN, A. A.; J. O. DE SOUZA; F. SEFFNER. Arqueologia de salvamento e a ocupação préhistórica do vale do Rio Pelotas. VERITAS, Porto Alegre, 1989, 35 (133): 99-127.

KINTIGH, K. The promise and challenge of archaeological data integration. American Antiquity, 2006, 7 (13): 567-578. 
KRISTIANSEN, K. Contract archaeology in Europe: an experiment in diversity. World Archaeology, 41(4): 641-648, 2009.

McMANAMON, Francis P. Digital Antiquity and the Digital Archaeological Record (tDAR): Broadening Access and Ensuring Long-Term Preservation for Digital Archaeological Data. The CSA Newletter, 23 (2), 2010.

McMANAMON, Francis P.; Keith W. KINTIGH. DIGITAL ANTIQUITY - Transforming archaeological data into knowledge. The SAA Archaeological Record, 2010, 10 (2): 37-40.

McMANAMON, Francis; Jode A. BARNES; Andrew STOUT. Introduction: Contemporary Archaeological Resource Management and the 'Liberals' Dilemma'. In: McMANAMON, Francis; Jode A. BARNES; Andrew STOUT, 2008: 17-33.

MERRIMAN, N. J. The Role of Museums. In: D. L. HARDESTY (Ed.), Archaeology, v. 2. UNESCO/EOLSS, 2001. Disponível em: <http://www.eolss.net/sample-chapters/c04/E6-2104-02.pdf>. Acesso em: outubro/2015.

MARTINEZ, D.B. Conocimiento y acción en la Arqueología Aplicada. Complutum, 2006, 17: 205-219.

MILLER, E. T. Inventário arqueológico da bacia e sub-bacias do Rio Madeira. São Paulo, CNEC, 1987.

MORAES WICHERS, C. A. de. Museus e antropofagia do patrimônio arqueológico: (des) caminhos da prática brasileira. Lisboa: Universidade Lusófona de Humanidades e Tecnologias, 2010. (Tese de Doutorado em Museologia).

OLIVEIRA, Vania D. E. de A pesquisa sobre o Acervo. In: Anais do IV Seminário sobre Museus-Casa. Edições Casa de Rui Barbosa, Rio de Janeiro, 2000: 106-112.

RUIZ, Rafael Azuar. Museos, arqueologia, democracia y crisis. Gijón: Ediciones Trea, 2013.

SANTOS, Maria do Carmo Mattos Monteiro dos. Musealização em projetos de arqueologia consultiva: perspectivas patrimoniais para a Estrada de Ferro Carajás (MA/PA). Lisboa: Universidade Lusófona de Humanidades e Tecnologias, 2011. (Tese de Doutorado em Museologia). 


\section{Revista de Arqueologia Pública}

SANTOS, Maria Célia T. Moura. Um compromisso social com a museologia. In: Cadernos do CEOM, 41, 2014: 71-114

SCHIFFER, M.; GUMERMANN (Ed.), Conservation Archaeology. New York, Academic Press, 1977.

SCHMITZ, P. I. Trabalho de salvamento arqueológico nos locais das represas do alto Uruguai, RS/SC. In: ELETROSUL, Bacia Hidrográfica do Rio Uruguai: Estudo de Inventário Hidroenergético, Apêndice IV e V. Florianópolis, ELETROSUL, 1978: 93-97.

SERRA, Ordep (Org). O Simbolismo da Cultura. Salvador: EDUFBA, 2001.

SILVA, Catarina E. F. da; LIMA, Francisca H. B. A preservação dos registros documentais de Arqueologia in: Revista do Patrimônio Histórico e Artístico Nacional, n. 33, 2007.

SIMÕES, M. F. Salvamento arqueológico em Carajás. In: Carajás Desafio Político, Ecológico e Desenvolvimento. São Paulo, Brasiliense, 1986.

SIMÕES, Mário F. \& ARAUJO-COSTA, F. Pesquisas arqueológicas no Baixo Tocantins (Pará). Revista de Arqueologia. Belém, CNPq/Museu Paraense Emílio Goeldi, 1987, 4 (1): 11-27.

SOUSA, Ana C. de. Arqueologia da Paisagem e a potencialidade interpretativa dos espaços sociais. Habitus, 3 (2): 291-300.

ZULAUF, W.E. O meio ambiente e o futuro. Estudos Avançados, USP, 2000, 14 (39), versão on line (http://www.scielo.br/scielo.php?script=sci_arttext\&pid=S010340142000000200009).

WAGSTAFF, J. M. Landscape \& Culture: Geographical \& Archaeological Perspectives. London, Blackwell, 1987. 